\title{
El acceso y la integración de los estudiantes con discapacidad en la Universidad de León
}

\section{The access and the integration of the students with dissability of Leon's University}

\author{
Eva María NAVA-CABALLERO \\ Universidad de León
}

Recibido: Enero 2011

Aceptado: Febrero 2012

\section{Resumen}

En este artículo se analiza la percepción que tienen los estudiantes con discapacidad de la Universidad de León sobre sus posibilidades de acceso e integración en los estudios superiores. Siguiendo una metodología correspondiente al estudio de casos, se ha recogido la opinión de un $14 \%$ de los estudiantes con discapacidad matriculados en la citada universidad tomando como instrumento de recogida de información la entrevista en profundidad. Los resultados indican que la edad, el sexo, el tipo, grado y momento de aparición de la discapacidad no parecen condicionar el nivel de integración de este colectivo.

Palabras clave: Estudiantes con discapacidad, estudios superiores, integración, acceso a la Universidad

\begin{abstract}
This article analyzes the perception that the students with disability of Leon's University have about their possibilities of access and integration in Higher Studies. Following a methodology corresponding to the Case Study, it has been gathered the opinion of $14 \%$ of the students with disability registered in that university taking the interview as an instrument to withdraw information in depth. The results indicate that the age, the sex, the type, the degree and the moment of appearance of the disability do not seem to determine the level of integration of this group.
\end{abstract}

Keywords: students with disability, Higher Studies, integration, access to University.

En los últimos años estamos presenciando transformaciones importantes en la atención socio-educativa que reciben las personas con discapacidad. En el ámbito universitario, la presencia de estudiantes con discapacidad en las aulas está aumentando considerablemente. En el año 2008 había 3.847 .900 personas con discapacidad en España (un 9\% de la población), de las cuales, 15.000 estaban realizando estudios universitarios; cifra que supera ampliamente a los 9.317 que cursaban este tipo de estudios durante el curso 2003/04.

A pesar del incremento de estudiantes con discapacidad en las universidades de nuestro país, muchas de ellas aún no están preparadas para atender a este colectivo, no 
sólo en lo referente a barreras arquitectónicas, sino también en lo relativo a aspectos curriculares o de organización. Generalmente, el aula no dispone de los recursos necesarios para favorecer la inclusión de este alumnado y el profesor imparte las clases utilizando una metodología poco adecuada para favorecer la participación de los estudiantes con discapacidad. Por lo tanto, este colectivo no se encuentra en igualdad de oportunidades respecto a sus compañeros (Castellana y Sala, 2006).

La accesibilidad de los centros universitarios españoles deja mucho que desear y las barreras arquitectónicas que existen en la mayor parte de los edificios universitarios, en algunos casos, agravan la minusvalía de los estudiantes con discapacidad (Alcantud, Ávila y Asensi, 2000). Estas barreras, unidas a las escasas relaciones sociales que generalmente presenta este colectivo, hacen que su paso por los estudios superiores conlleve una gran cantidad de dificultades. Para solventar estos impedimentos, la mayor parte de las universidades españolas han creado servicios de apoyo a los alumnos con discapacidad, que, salvando las diferencias que pueda haber entre una universidad y otra, realizan las siguientes actividades: elaborar un censo de estudiantes con discapacidad, eliminar las barreras arquitectónicas y de comunicación, informar sobre las prestaciones económicas, gestionar el préstamo de ayudas técnicas, sensibilizar a la comunidad universitaria fomentando actitudes positivas hacia la discapacidad, promover la acción del voluntariado en el ámbito universitario y fomentar la investigación sobre temas relacionados con la discapacidad.

La Universidad de León, al igual que el resto de universidades, ha visto como el porcentaje de alumnado con discapacidad se está incrementando en sus aulas, exceptuando el curso 2009/10, que, como podemos observar en los siguientes gráficos, disminuyó el número total de alumnos matriculados en esta universidad y también el de alumnos con discapacidad. El porcentaje de estudiantes con discapacidad ha pasado del $0,51 \%$ del total en el curso 2008/09, al 47\% durante el curso 2009/10 para consolidarse en un $0,56 \%$ durante los dos últimos cursos.

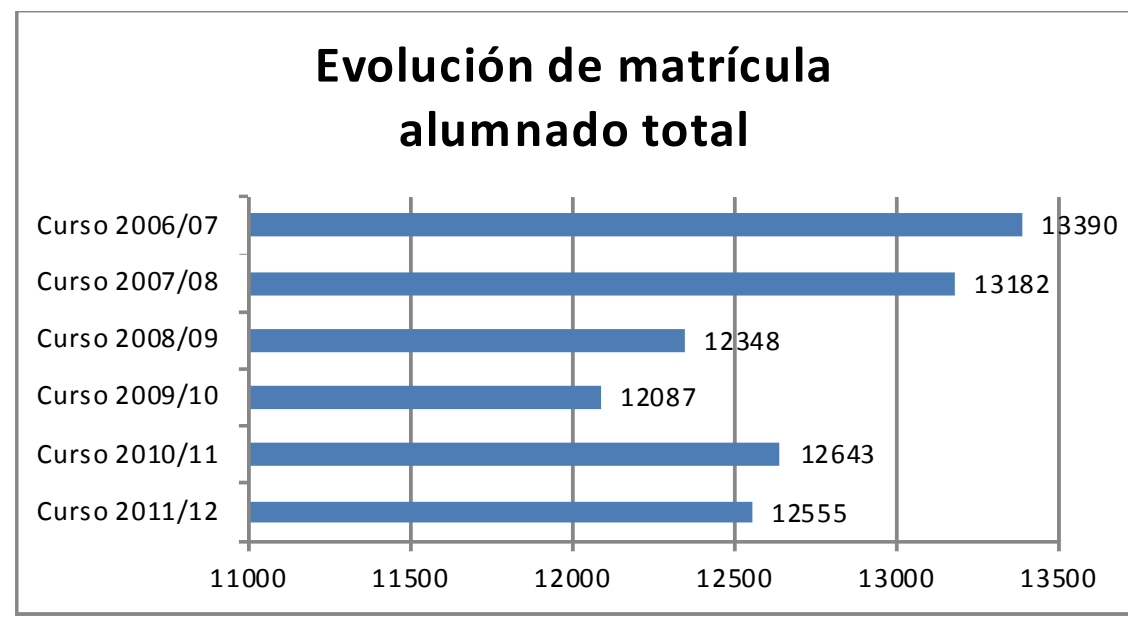




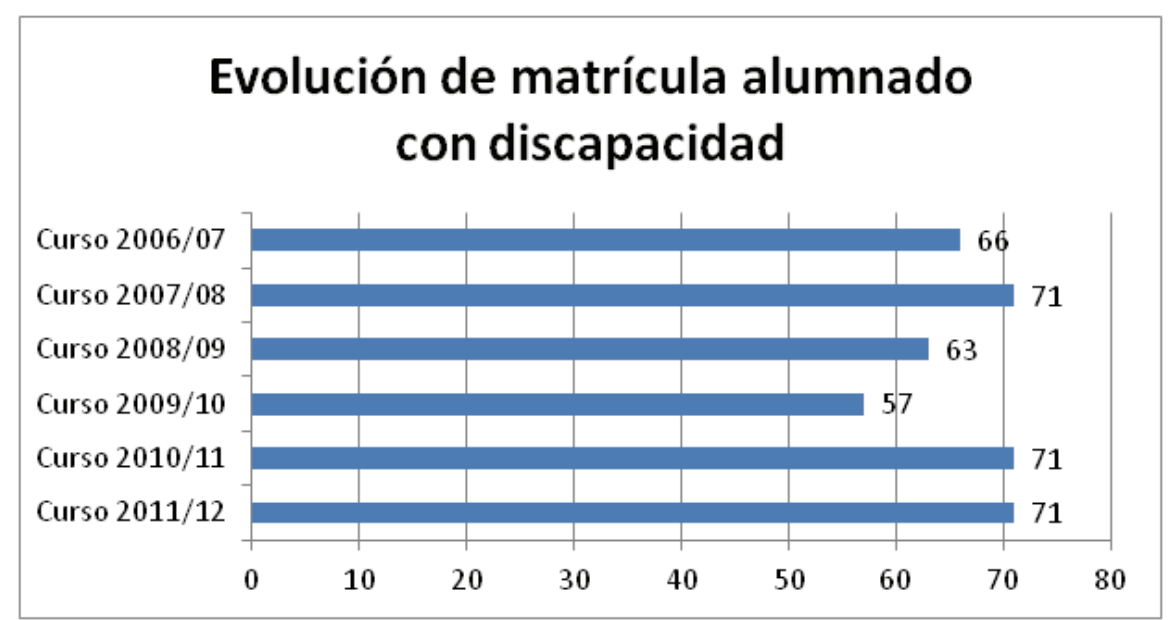

Gráficos 1 y 2. Evolución del número de alumnos con discapacidad y del número total de alumnos matriculados en la Universidad de León.

\section{Planteamiento del problema}

Cada vez es más frecuente encontrar alumnos con discapacidad en las aulas de las universidades españolas, sin embargo, todavía se siguen presentando condiciones sociales desventajosas que no siempre se deben a las consecuencias de tener deficiencias físicas, psíquicas o sensoriales (De la Red, De la Puente, Gómez y Carro, 2002). Aunque el derecho a la igualdad de oportunidades figura en numerosas leyes de nuestro ordenamiento, si no se produce una verdadera actitud de apoyo social a las personas con discapacidad, éstas seguirán teniendo muchas dificultades para acceder a los estudios superiores. Ante esta situación nos preguntamos cuál sería el nivel de integración de los estudiantes con discapacidad de la Universidad de León y si tendrían dificultades para acceder a los estudios superiores; respuestas que obtuvimos al finalizar la presente investigación.

\section{Objetivos de la investigación}

El objetivo general de la investigación es descubrir la percepción que tienen los estudiantes con discapacidad de la Universidad de León sobre sus posibilidades de acceso e integración en los estudios superiores. De manera más específica, hemos querido conocer su opinión sobre las adaptaciones curriculares, el trato recibido por parte del profesorado y de sus compañeros, las actividades lúdicas y deportivas en las que participan y las propuestas de mejora para garantizar una adecuada convivencia dentro de la comunidad universitaria. Por este motivo, el objetivo general, mencionado anteriormente, puede perfilarse en los siguientes objetivos específicos:

- Conocer los apoyos o limitaciones de los estudiantes con discapacidad para acceder a los estudios universitarios. 
- Determinar las posibilidades de promocionar de este colectivo.

- Valorar la opinión de los estudiantes con discapacidad sobre el profesorado: sus necesidades de formación, sus recursos, su comportamiento, etc.

- Conocer la opinión de los estudiantes con discapacidad sobre el grado de sensibilización del resto de miembros de la comunidad educativa.

- Saber el nivel de participación de los estudiantes con discapacidad en las actividades lúdicas y deportivas organizadas por la universidad.

- Conocer las propuestas de mejora que, en opinión de los estudiantes con discapacidad, debería tomar la Universidad para mejorar el acceso y la integración de los mismos.

\section{Metodología}

Esta investigación, de naturaleza cualitativa, se ha realizado a través de un estudio de caso, método que consiste en la búsqueda de soluciones a través de la discusión y el análisis de un problema dentro de un grupo, bien sea de carácter real o simulado (Pérez Serrano, 1994). Hemos seleccionado el estudio de caso por su flexibilidad para ser aplicado a situaciones naturales y por ser una técnica que permite indagar y analizar en profundidad la realidad objeto de estudio. El estudio de caso es apropiado para investigaciones a pequeña escala, con un marco limitado de tiempo, espacio y recursos (Del Rincón, Latorre, Arnal y Sans, 1995); características que son perfectamente aplicables a esta investigación. Merriam (1988, en Arnal, Del Rincón y Latorre, 1994) señala cuatro propiedades esenciales del estudio de caso:

- Particular: porque se centran en una situación, evento, programa o fenómeno particular. El caso en sí mismo es importante por lo que revela acerca del fenómeno y por lo que pueda representar.

- Descriptivo: el producto final de un estudio de caso es una descripción amplia del fenómeno objeto de estudio; una descripción que suele ser de tipo cualitativo.

- Heurístico: los estudios de caso pueden dar lugar al descubrimiento de nuevos significados, ampliar la experiencia del lector o confirmar lo que ya sabe. Por tanto, pueden aparecer relaciones y variables no conocidas anteriormente que provoquen un replanteamiento del fenómeno.

- Inductivo: los estudios de casos se basan en el razonamiento inductivo; los conceptos o las hipótesis surgen de un examen de los datos fundados en el contexto mismo. El estudio de caso se orienta más al descubrimiento de nuevas relaciones y conceptos, que a la verificación de hipótesis predeterminadas. 


\section{Características de la muestra}

La muestra está formada por 9 alumnos con discapacidad, de los 71 que actualmente están matriculados en la Universidad de León, lo que supone un 12,7\% de la población objeto de estudio. Teniendo en cuenta el tipo de discapacidad, han sido entrevistados dos alumnos con deficiencia visual, una con deficiencia auditiva, una con discapacidad psíquica y cinco con discapacidad física.

\begin{tabular}{|c|c|c|c|c|}
\hline $\begin{array}{c}\text { Tipo de } \\
\text { discapacidad }\end{array}$ & $\begin{array}{c}\text { Deficiencia } \\
\text { Visual }\end{array}$ & $\begin{array}{c}\text { Deficiencia } \\
\text { Auditiva }\end{array}$ & $\begin{array}{c}\text { Discapacidad } \\
\text { Psíquica }\end{array}$ & $\begin{array}{c}\text { Discapacidad } \\
\text { Física }\end{array}$ \\
\hline $\mathrm{N}^{\mathrm{o}}$ Entrevistados & 2 & 1 & 1 & 5 \\
\hline
\end{tabular}

Tabla 1. Distribución de la muestra de estudiantes con discapacidad según el tipo de discapacidad

En cuanto al sexo, conviene destacar que, a pesar de que en la Universidad de León, un $61 \%$ de los alumnos con discapacidad son hombres, frente a un $39 \%$ de mujeres; en este estudio han participado siete alumnas y dos alumnos, cuyas edades están comprendidas entre los 19 y 42 años.

Otra de las variables a considerar es el tipo de carrera universitaria que está realizando cada uno de estos alumnos. En este aspecto podemos mencionar que un alumno está realizando estudios de doctorado en el programa de Psicología y Educación, otro Derecho, otro Ciencias del Trabajo, otro Relaciones Laborales, otro Magisterio, otro Ingeniería Aeronáutica, otro Veterinaria y dos Trabajo Social.

\begin{tabular}{|c|c|}
\hline Estudios Realizados & Número de entrevistados \\
\hline Doctorado (Psicología y Educación) & 1 \\
\hline Derecho & 1 \\
\hline Ciencias del Trabajo & 1 \\
\hline Relaciones Laborales & 1 \\
\hline Magisterio & 1 \\
\hline Ingeniería Aeronáutica & 1 \\
\hline Veterinaria & 1 \\
\hline Trabajo social & 2 \\
\hline
\end{tabular}

Tabla 2. Distribución de la muestra de estudiantes con discapacidad según los estudios realizados 


\section{Diseño de la investigación}

El diseño y desarrollo de la parte empírica de este trabajo se ha ido realizando de forma paralela a la elaboración del marco teórico, Aún así, se pueden diferenciar una serie de fases, con sus tareas correspondientes, que configuran el itinerario seguido en el proceso investigador. En el siguiente esquema quedan recogidas las principales actividades llevadas a cabo.

\begin{tabular}{|l|l|}
\hline $\begin{array}{l}\text { Fase } 1 \\
\text { Preparación de la investigación }\end{array}$ & $\begin{array}{l}\text { - Revisión bibliográfica. } \\
\text { - Acotación del problema de estudio. } \\
\text { - Planteamiento de los objetivos. } \\
\text { - Seleción de la metodología. }\end{array}$ \\
\hline $\begin{array}{l}\text { Fase } 2 \\
\text { Elaboración y aplicación de los instrumentos de las muestras. } \\
\text { de recogida de la información }\end{array}$ & $\begin{array}{l}\text { - Edición de entrevistas } \\
\text { - Aplicación de las entrevistas a la muestra. }\end{array}$ \\
\hline $\begin{array}{l}\text { Fase } 3 \\
\text { Recogida y análisis de datos }\end{array}$ & $\begin{array}{l}\text { - Recogida de 9 entrevistas. } \\
\text { - Codificación de los datos. }\end{array}$ \\
\hline $\begin{array}{l}\text { Fase } 4 \\
\text { Interpretación de la información y } \\
\text { elaboración de conclusiones }\end{array}$ & - Análisis de los datos. \\
\hline
\end{tabular}

Tabla 3. Itinerario seguido en el proceso investigador.

\section{Técnica de recogida de información y procedimientos de análisis}

El instrumento de recogida de información utilizado para realizar esta investigación ha sido la entrevista, en este caso semiestructurada y en profundidad. Se ha utilizado este instrumento porque la entrevista permite recoger información sobre acontecimientos y aspectos subjetivos de las personas: creencias y actitudes, opiniones, valores o conocimientos, que de otra manera no estarían al alcance del investigador (Del Rincón, Latorre, Arnal y Sans, 1995). En el momento de realizar las entrevistas, se parte de un guión previamente definido, pero se permite que los entrevistados hablen extensamente, y a partir de sus respuestas, surgen nuevas preguntas, que en algunos casos han sido de gran relevancia. Las cuestiones que se exponen en ningún caso pueden resolverse únicamente con monosílabos y todas tienen una clara intención. Los lugares donde se han realizado las entrevistas han sido variados: facultades, cafeterías, casas de los entrevistados, etc. También se ha hecho 
uso de la observación, que junto con la información aportada en las entrevistas, ha permitido una interpretación más profunda de los datos.

La entrevista utilizada estaba estructurada en seis apartados: acceso a los estudios superiores, acceso al currículo, relación con el profesorado, relación con el resto de compañeros, participación en actividades lúdicas y deportivas organizadas por la Universidad de León y propuestas de mejora. Siguiendo la metodología de Miles y Huberman (1994), para sintetizar los datos obtenidos, utilizamos la categorización, en este caso mediante el procedimiento de sistemas emergentes, es decir, que no existían categorías previas, sino que éstas surgían a medida que se iba realizando la lectura del texto transcrito de la entrevista. Esta categorización o codificación del texto convierte las formulaciones coloquiales e individuales, pertenecientes al lenguaje diario, en un sistema de notaciones menos complejo y ambiguo.

Las entrevistas, cuya duración media fue de cuarenta y cinco minutos, fueron realizadas individualmente, grabadas en audio y posteriormente transcritas. Una gran ventaja de la entrevista en directo es que se pueden captar múltiples informaciones propias de la riqueza expresiva del lenguaje verbal. Para analizar el contenido de las entrevistas se han establecido diferentes categorías en función de las respuestas obtenidas. A continuación detallamos las categorías utilizadas en el presente estudio.

En el apartado de acceso a los estudios superiores seleccionamos las categorías: modo de acceso, objeciones o limitaciones encontradas, gratuidad de la matricula como condicionante del número de alumnos matriculados y ayuda durante el proceso de matriculación. En el apartado de acceso al currículo destacamos: necesidad de adaptaciones curriculares, adaptación de los contenidos para personas con discapacidad, necesidad de más esfuerzo para finalizar los estudios debido a la discapacidad, posibilidad de promocionar y posibilidades de encontrar trabajo con una discapacidad.

En la parte referente a la relación con el profesorado se encuentran las siguientes categorías: trato recibido por parte del profesorado, ayuda en exceso por parte del profesorado, necesidad de formación del profesorado en materia de discapacidad, recursos de la Universidad para dar clase a alumnos con discapacidad, aumento del trabajo a los profesores que tienen alumnos con discapacidad en sus clases y sensación de discriminación por parte del profesorado. En el apartado de relación con el resto de compañeros seleccionamos las categorías: sentimiento de discriminación por parte de los compañeros, dificultades de los compañeros para iniciar una conversación con un estudiante con discapacidad, grado de sensibilización de los estudiantes universitarios y relación con otros estudiantes con discapacidad.

En cuanto a las actividades en las que participan, las categorías son: utilización de la Unidad de Apoyo a Estudiantes con Discapacidad, pertenencia a alguna asociación relacionada con su discapacidad, participación en actividades lúdicas o deportivas y participación en programas de movilidad estudiantil. Finalmente en el apartado de propuestas de mejora, categorizamos los datos en función de su relación con la accesibilidad o con la integración. 


\section{Resultados}

Los resultados de la investigación se obtienen del análisis cualitativo de las respuestas dadas a las cuestiones planteadas. A continuación, mediante diferentes apartados, recogemos los principales resultados de este estudio.

\section{Acceso a los estudios universitarios}

Existe una gran variedad de opiniones a la hora de describir el motivo por el que las personas entrevistadas decidieron realizar los estudios universitarios que están cursando. Merece la pena destacar que ninguno de ellos comentó que su intención fuera, en un futuro, incorporarse al mundo laboral en algún puesto de trabajo relacionado con los estudios que están realizando.

Un $66 \%$ de los estudiantes entrevistados señala que opta por esos estudios ya que eran los que más le gustaba teniendo en cuenta sus limitaciones, así una de las estudiantes destaca: "cuando mis hijos fueron un poco mayores, decidí que podía hacer algo y siempre me atrajeron las series de televisión que iban de leyes, de abogados y pensé que para una persona ciega, el derecho no era una carrera demasiado complicada".

E1 22\% de los alumnos entrevistados, además de sentir atracción por los contenidos de sus respectivas carreras, considera que se matriculó en esos estudios porque le suponía un reto; una de las estudiantes con deficiencia visual señala: "a mi me gustaba el inglés, siempre me han gustado los idiomas, y decidi estudiar inglés un poco por rebeldia, porque hubo gente que dudaba de mis capacidades para poder aprender un idioma". De manera similar, otra alumna destaca: "otro factor que me influyó enormemente fue, que por aquella época, se decía que era una de las carreras más difíciles y ello me suponía un reto". Los demás alumnos se decantaron por otras opciones como: "básicamente para ocupar el tiempo" o "para tener más formación".

Todos los alumnos entrevistados destacan que no tuvieron ningún tipo de objeción o limitación por parte de su entorno familiar y social cuando decidieron matricularse en la Universidad, aunque uno de ellos señala: "mis padres me dijeron que estaba loco, que me dedicara principalmente al trabajo, pero yo pensé que si podía compatibilizarlo, lo intentaría, y eso es lo que hice". Una de las alumnas con deficiencia visual destaca el importante papel que desarrollaron sus padres al animarla a estudiar: "yo al principio estaba desmotivada para venir a la Universidad, no quería matricularme porque tenía miedo al cambio, a la nueva vida, y si no hubiese sido por los ánimos externos, no habría estudiado".

En lo referente al modo de acceso a los estudios universitarios, un $22 \%$ de los alumnos entrevistados accedió a los estudios haciendo uso de las plazas reservadas para estudiantes con discapacidad y el $78 \%$ restante siguió el procedimiento habitual (nota de selectividad o prueba equivalente, nota del expediente de otra diplomatura o licenciatura, nota de ciclos formativos, nota del curso de acceso para mayores de 25 años...). 
Algunos estudiantes con discapacidad necesitan ayuda a la hora de realizar la matrícula, sin embargo el $66 \%$ de los alumnos entrevistados señala que no tuvo ayuda porque no la necesitó. El 22\% indica que recibió ayuda por parte de becarios, del personal de la secretaria y en uno de los casos la alumna señala que también tuvo "el apoyo de la trabajadora social de la Universidad que se dedica a atender a discapacitados; ella me orientó un poco sobre el servicio que nos ofrece la Universidad". En cambio, una de las alumnas con deficiencia visual se queja por lo poco que se facilita la accesibilidad en este sentido:

Si lo que se pretende es que seamos independientes y la independencia tiene que ser integral, pues hay que ser integral; no en unos contextos sí y en otros no. Si se supone que yo tengo que ser independiente, también será en el aspecto burocrático, y por ejemplo, yo, para rellenar la matrícula, he necesitado la ayuda de mi madre, que me iba leyendo las asignaturas y a mí me parece que eso no debería ser así.

Todos los alumnos coinciden al afirmar que el hecho de que la matrícula en la Universidad sea gratuita para los estudiantes con discapacidad anima a este colectivo a realizar estudios universitarios, aunque varios estudiantes realizan algunas matizaciones que están relacionadas con sus situaciones personales; uno de ellos, en este caso, con discapacidad psíquica, comenta:

Mi enfermedad es oscilante... cuando estoy mal, me veo obligada a dejar los estudios, y entonces... si tuviera que pagar segunda o tercera matricula por cada curso que pasara, llegaría un momento en el que mis padres me plantearían dejar los estudios por la importante suma económica que esto supondría.

Otra estudiante destaca que "muchas personas con discapacidad no acceden a la Universidad por falta de oportunidades, lo de la gratuidad de la matrícula es un factor a tener en cuenta, pero creo que no lo es todo". Por otro lado, una de las entrevistadas, en este caso una persona con deficiencia visual, comenta que la gratuidad de la matrícula para los discapacitados "es un arma de doble filo; a lo mejor es tirar piedras contra mi propio tejado, pero considero que mucha gente se relaja un poco precisamente por eso. Recuerdo que antes, si no aprobabas un curso, tenías que pagar las segundas o terceras matrículas y yo considero que debería ser asi"."

\section{Acceso al currículo}

Para acceder al contenido de las asignaturas, un 33,3\% de los alumnos entrevistados indica que no necesitó ningún tipo de apoyo ni adaptación, a pesar de que reconoce ser más lento a la hora de tomar apuntes; una alumna con discapacidad física comenta:

Ahora me duelen un poco más las muñecas y los nudillos, voy un poco más despacio, pero puedo seguir el ritmo normal de la clase. Yo me defiendo y los exámenes los hago escritos, lo único diferente es que si el examen es en un aula en forma de semicírculo y por los apellidos, a mí me toca arriba, el profesor de turno me deja hacerlo en la primera fila porque a mí me cuesta mucho subir escaleras.

Otro 33,3\% señala que no necesita adaptación en lo referente al acceso a los contenidos, pero sí en lo relativo a la temporalización; es decir, dos de los estudiantes entrevistados señalan que, para realizar los exámenes les conceden más tiempo que a 
sus compañeros y otra alumna indica que cuando tiene una recaída y no puede acudir ese día al examen los profesores se lo posponen, "en lo que a mi respecta, todos los profesores me están ayudando mucho; su comprensión y entera disposición es lo que me anima a continuar adelante cuando ya no tengo fuerzas para nada".

Por otro lado, el $33,3 \%$ de los estudiantes entrevistados necesita adaptaciones a la hora de acceder al contenido de las asignaturas, un alumno con discapacidad física comenta: "yo escribo muy lento y no puedo seguir el ritmo normal de la clase, entonces, en algunos casos los profesores me dan el temario y en otros casos, los compañeros me pasan los apuntes. Los exámenes me los tienen que hacer orales". Una de las alumnas con deficiencia visual señala que, aunque toma apuntes, sus compañeros también la ayudan dictándole cosas. También comenta: "utilizo muchas fotocopias, escaneo muchísimo y tengo un programa de síntesis de voz en el ordenador que me va transformando en voz todo lo que está escrito"

Otra estudiante con deficiencia visual indica que en el tema del acceso a los contenidos "se ha creado una falsa accesibilidad porque no se tienen en cuenta las peculiaridades de cada persona". Contando su experiencia señala que:

El acceso a los apuntes tendría que hacerse desde otro punto de vista, no ir yo a la fotocopiadora, coger apuntes que yo obviamente no puedo leer porque están en tinta, y decirle a mi madre que me los grabe, como sucede en estos momentos... Es cierto que algunos profesores, cuando tienen los apuntes en formato digital, me los pasan, lo cual me facilita mucho la tarea porque mi ordenador cuenta con un programa de sintesis de voz que me va leyendo todo lo que aparece, pero esto pasa pocas veces, menos de las que debería de pasar.

Estos resultados contrastan con los obtenidos por Castellana y Sala (2006) en nueve universidades españolas, donde el $84 \%$ de los estudiantes expresa que tiene importantes dificultades para acceder a la información durante las clases debido a las dificultades para tomar apuntes.

La mayor parte de los alumnos entrevistados, en este caso un $88,8 \%$ considera que los contenidos deberían ser los mismos para las personas con discapacidad que para el resto de los estudiantes. Algunos de sus comentarios fueron: "yo creo que deberían ser los mismos, de hecho, me sentiria ofendida si no lo fueran" (alumna con deficiencia visual). Otra alumna con deficiencia visual señala:

Evidentemente, los contenidos tienen que ser los mismos, pero no la forma de transmitirlos; la falacia del alumno medio está ahi y no es cierta; el alumno medio nunca existe: ni en el colegio, ni en el instituto ni en la universidad; cada uno tenemos nuestra vía de aprendizaje y creo que el profesorado debería adaptarse más a cada alumno y considero que eso es posible. Además, si en otros paises sucede, aquí también podría suceder.

Otra alumna, en este caso, con deficiencia auditiva, comenta: "yo creo que los contenidos deberían ser los mismos porque tener una discapacidad no quiere decir que estén afectadas tus capacidades mentales". El 11,2\% restante considera que "en el caso de personas que tienen un déficit intelectual, se podrían adaptar los contenidos un росо". 
En lo referente a las limitaciones que puedan sufrir los alumnos entrevistados a la hora de hacer frente a los estudios en los que están matriculados, el 66,6\% de ellos piensa que su discapacidad no le impide terminar los estudios de la misma manera y en el mismo tiempo que al resto de sus compañeros. Una alumna con deficiencia visual comenta: "yo creo que es cuestión de trabajo, a mi seguramente me cuesta más por la edad, pero no por la discapacidad". Otra alumna, en este caso, con una discapacidad física, señala que "tardaría los mismos años en hacer la carrera si no tuviera la discapacidad... porque con trabajo, sacrificio y voluntad, todo se saca".

Sin embargo, el 33,4\% de los alumnos entrevistados afirma que debido a su discapacidad, le cuesta más terminar los estudios que al resto de sus compañeros. Una alumna con discapacidad psíquica comenta:

Mi inteligencia no se ha visto mermada por padecer esta enfermedad, pero como la inteligencia no es solamente el nivel cognitivo que poseas, sino que el ámbito emocional la condiciona enormemente, yo no rindo de la misma manera cuando estoy bien que cuando estoy depresiva. Soy incapaz de mantener la concentración y no consigo memorizar nada. Además, algunos de los medicamentos que tomo perjudican la memoria a corto plazo y disminuyen la concentración.

Otra alumna, en este caso con una discapacidad física, señala que le cuesta más terminar sus estudios porque no puede estar mucho tiempo sentada (algo que considera necesario para conseguir concentrarse cuando está estudiando); “yo, aunque tuviera 24 horas libres al día para estudiar, no podría meterme cinco horas en una biblioteca porque igual luego me toca estar tres o cuatro días en la cama". Otro alumno con discapacidad física considera que su discapacidad le impide terminar los estudios en el mismo tiempo que los demás compañeros porque está "continuamente de bajas, con brotes, hospitalizado".

Casi todos los alumnos entrevistados (un 88,8\%) consideran que tienen las mismas posibilidades de promocionar que el resto de sus compañeros, aunque tarden más años en terminar los estudios; en cambio, un $11,2 \%$ piensa que no tiene las mismas posibilidades. Una alumna con discapacidad psíquica comenta: "si tu discapacidad ya es un obstáculo para ti mismo, para los demás también. Los prejuicios y la falta de tolerancia en una sociedad que sólo busca el beneficio económico en la rentabilidad de los trabajadores, es determinante para nosotros".

Sin embargo, al hablar de las ventajas o inconvenientes que tendría su discapacidad a la hora de buscar trabajo, sus respuestas son más heterogéneas. El 44,4\% de los alumnos entrevistados considera que actualmente, con la legislación que existe en España, el hecho de tener una discapacidad le ayudaría a encontrar un trabajo. Algunos de sus comentarios fueron los siguientes:

Yo saqué la plaza de administrativo por el apartado de discapacidad. En total habia 13 plazas y una de ellas era para personas con discapacidad y yo la saqué por eso, si no, no la saco. Exigen lo mismo, pero al haber menos gente compitiendo, es más sencillo. Nosotros nos presentamos 70 para una plaza, que éramos bastantes. En el primer examen yo saqué un 5,9 y me sirvió para pasar, mientras que había gente con un 8 en el apartado libre, que no pasaba al siguiente examen porque eran 1500 o 2000 
personas las que se presentaron para esas 12 plazas" (alumno con discapacidad fisica).

Otra alumna con discapacidad física, señala: "está mal que yo lo diga, pero, con mi discapacidad, no creo que tuviera problema en encontrar un trabajo". Una alumna con discapacidad auditiva comenta que "a la hora de buscar trabajo, con las ayudas que hay ahora, si me favorecería tener discapacidad".

Por otro lado, un 22,2\% considera que el hecho de tener discapacidad no supone una ventaja a la hora de encontrar un trabajo, una alumna, con discapacidad psíquica, comenta:

Según tengo entendido, si vas a presentarte a una oposición, aunque haya un porcentaje de plazas destinadas a personas con discapacidad, es mejor no optar a ellas, ya que ponen pegas a estos opositores. Una vez que no se hayan cubierto esas plazas, al no haber sido considerados como aptos los opositores con discapacidad, esas plazas pasarán a cubrirse por el resto de personas. Es decir, prefieren a una persona sin discapacidad con un 5, que a un discapacitado que saque un 10. Es injusto desde el punto de vista de la igualdad de derechos, pero si miran la rentabilidad de un funcionario, es algo obvio actuar así.

Otra alumna, en este caso una estudiante con deficiencia visual, señala que no se ha planteado cómo sería el acceso al trabajo, pero supone que "habrá la mismas barreras que siempre"; destaca: "yo quiero conseguirlo, quiero formar parte activa en la sociedad y demostrar que una persona discapacitada puede trabajar; que no tenga que hacer méritos extra para demostrar que vale; sino que por sus propios méritos pueda demostrar que vale igual que el resto". El 33,4\% restante, indica que no sabe si tener una discapacidad ayuda a encontrar trabajo o es un obstáculo (dos de ellos tienen una invalidez, una jubilación reconocida; por lo que no se plantean volver a trabajar). Una de las alumnas con discapacidad física señala: "mi madre me anima a que prepare unas oposiciones porque hay unas plazas reservadas para minusválidos, pero no sé si sería más difícil o más fácil encontrar trabajo”.

\section{Relación con el profesorado}

La mayor parte de los alumnos entrevistados, un 88,8\% considera que los profesores no le tratan de manera diferente por tener una discapacidad, aunque alguno de ellos realiza ciertas matizaciones: "yo creo que si alguna vez me han tratado de forma diferente ha sido por un problema personal de ellos. Nunca o en muy pocas ocasiones he sentido que me traten de forma distinta, pero lo que si hay es mucha desinformación por parte de ellos y afrontan el tratar con una persona con discapacidad con mucho miedo" (alumna con discapacidad visual).

El 11,2\% restante piensa que quizá inconscientemente le tratan de manera diferente, un alumno con discapacidad física indica:

Yo creo que te tratan un poco mejor; estoy pensando en un caso en concreto, con un profesor que a lo mejor tengo más empatía con él porque padece una enfermedad 
neurológica, entonces, al verte también fastidiado te pregunta qué te ha pasado y te dice: a mí me pasa esto... Yo tampoco pretendo tener más ventajas por el hecho de estar así, para nada. Me parece bien que me faciliten las cosas en cuanto apuntes, pero nada más.

En lo referente a una posible ayuda en exceso por parte del profesorado, los resultados son los mismos: un $88,8 \%$ opina que no ha recibido más ayuda de lo considerado dentro de los límites de la normalidad, aunque una de las alumnas indica: "no en exceso no, pero me han cuidado" (alumna con discapacidad física), y otra de ellas señala: "hay profesores en la Universidad, aunque no todos, que me han sorprendido enormemente al dejar ver su gran calidad humana una vez que han conocido mi problema" (alumna con discapacidad psíquica).

Respecto a las necesidades de formación del profesorado en materia de discapacidad, un 66,6\% de los alumnos considera que los profesores deberían recibir algún tipo de formación para tratar a los estudiantes con discapacidad. Una alumna con deficiencia visual señala: "los profesores deben aprender las particularidades del alumno, no que el alumno se adapte; sino que ellos adapten su metodología al alumno porque de esta manera se conseguirían tres cosas: más motivación del alumno, más acceso de personas con discapacidad a la Universidad y mejor formación del alumnado".

Varios estudiantes entrevistados indican que sería conveniente que los profesores recibieran algún curso, uno de ellos comenta que les deberían enseñar " a tratar a la gente con discapacidad para que no les 'hagan de menos' y sepan valorar las limitaciones de cada persona" (alumno con discapacidad física). Otra alumna comenta que deberían aprender a "tener más concienciación porque a veces una palmadita en la espalda te viene bien” (alumna con discapacidad física). Una alumna con deficiencia visual opina que "deberían hacer un curso global de todas las capacidades y después, dependiendo de los alumnos que tengan, ofrecerles un poco de información, en mi caso, señala, para que los profesores sepan cómo trabaja una persona ciega, aunque no trabajamos todos de la misma manera".

Por otro lado el 33,4\% restante considera que no es necesario que los profesores reciban más formación; una alumna con deficiencia auditiva opina: "yo creo que deberian tener la información suficiente para saber cómo actuar, pero tampoco una formación específica y especial para eso". En la misma línea, una alumna con discapacidad física, comenta que no sería de gran utilidad porque "si a un profesor se le presenta un alumno con una discapacidad en clase, por mucha formación que tenga, nunca sabes cómo va a reaccionar ese alumno. Puede haber dos personas con la misma discapacidad, pero ser como el día y la noche; totalmente opuestos".

Estos resultados son similares a los obtenidos por López, Felipe, Ruiz y Vicente (2006) en un estudio realizado en la Universidad de Extremadura, en el que los alumnos con discapacidad señalan la falta de formación de los profesores en necesidades educativas. Lo mismo sucede con un estudio realizado por Sánchez (2009) en la Universidad de Almería, donde se indica que el 70\% de los estudiantes 
con discapacidad de esta Universidad está de acuerdo con desarrollar una formación específica del profesorado universitario para trabajar con ellos.

Por otro lado, las opiniones de todos los entrevistados coinciden con las conclusiones expuestas por Alcantud, Ávila y Asensi (2000) donde explican que la responsabilidad de la adaptación no debe recaer exclusivamente en el profesor responsable de la materia, que en muchos casos no tiene formación específica sobre las características de la discapacidad del estudiante, sus posibilidades ni conocimientos de otras experiencias. Debe ser el departamento con responsabilidad docente en el área de conocimiento que se trate, el que corporativamente avale la adaptación necesaria, contando para ello con la colaboración del personal experto de apoyo de los correspondientes servicios de apoyo de la Universidad.

Al hablar de recursos de la Universidad y barreras arquitectónicas, el 88,8\% de los alumnos entrevistados piensa que la Universidad no cuenta con los recursos necesarios para dar clase a alumnos con discapacidad y que en sus edificios hay muchas barreras arquitectónicas. Una alumna con deficiencia visual comenta:

La verdad es que yo he comentado este tema con algunos profesores y ellos también se quejan de esto, me dicen que ellos querrían adaptarse a cada alumno, pero que no tienen los recursos pertinentes. Algunos profesores me han comentado que les encantaría darme los apuntes en braille, pero que no tienen los recursos para hacerlo. En cuanto a barreras arquitectónicas, la verdad es que algunos accesos dejan bastante que desear, sobre todo los nuevos, algo que no me lo puedo explicar.

Otra alumna con deficiencia visual señala:

La Universidad no está adaptada, ni mucho menos, especialmente la Facultad de Derecho, con esas aulas semicíclicas que tiene. No me parece que estén bien las aulas, la acústica no es buena y muchas veces escriben cosas en la pizarra y yo tengo que depender de mis compañeros para que me lo digan o el profesor de turno, si se acuerda, lo dice en voz alta para que yo lo pueda coger. A pesar de esto, yo no he notado demasiadas dificultades, de hecho, ahora con las nuevas tecnologías, los profesores me mandan mensajes a través del correo electrónico y a mí la ONCE me ha provisto de todo tipo de tecnología, asi que, en este sentido, soy una privilegiada.

Sobre las barreras arquitectónicas, una alumna con discapacidad física indica:

La Universidad es una auténtica trampa por todos los lados, la nueva Facultad de Educación, por ejemplo, ¿cómo ponen esas escaleras en una facultad?, ¿cómo se sube por ellas?, ¿cómo ponen el ascensor detrás de una puerta de emergencia?... Yo no digo que, por ejemplo, el rectorado, que es un edificio antiguo, haya que tirarlo, se adapta lo que se pueda, pero esta facultad que es un edificio nuevo, ¿cómo puede tener las barreras que tiene?

También comenta que la mayoría de las rampas tienen mucha pendiente y que en muchas escaleras no hay barandillas, por lo que para ella es muy difícil acceder a algunos edificios.

Otro alumno con discapacidad física señala: "yo creo que no hay suficientes recursos y hay muchas barreras arquitectónicas; en la Escuela de Trabajo Social no 
hay nada adaptado. Yo comenté una vez que si podían bajar la clase de primero a la planta baja y me contestaron que mientras no pudiera ir al aula que era, que fuera a tutorías". Otra alumna, sobre este mismo edificio indica: "los edificios del campus, no sé, pero desde luego, la Escuela de Trabajo Social no está adaptada, es un edificio antiguo y no hay ni rampas ni ascensor, si viene alguien en silla de ruedas, no sé que tendría que hacer".

Por otra parte, una alumna con discapacidad física señala que "aunque la Universidad no disponga de todos los recursos necesarios, las asociaciones de las diferentes discapacidades facilitan a los alumnos afectados material específico para que puedan seguir las clases de la mejor manera posible". Otro alumno con discapacidad física comenta que aunque el campus tiene bastantes barreras, él ha tenido suerte: "en la Facultad de Relaciones Laborales hay un baño adaptado, hay un ascensor y rampas. La clase en la que estoy está en pendiente, por lo que tengo que quedarme abajo y hay poco espacio con la tarima, pero bueno, son problemas menores". El 11,2\% restante indica que no lo sabe: "supongo que en un momento dado, (la Universidad) pondría los recursos necesarios para la persona que lo necesitara" (alumna con deficiencia auditiva).

La valoración que hacen los estudiantes con discapacidad de la Universidad de León sobre los obstáculos físicos nos permite afirmar la existencia de una analogía con otros estudios realizados, como los elaborados por: De la Red, De la Puente, Gómez y Carro (2002) en la Universidad de Valladolid; Díaz (2004) en las Palmas de Gran Canaria; López y Polo (2006) en la Universidad de Granada; Rodríguez, Romero y Luque (2006) en la Universidad de Málaga y Bilbao (2008) en la Universidad de Burgos.

La mayor parte de los alumnos entrevistados, un $88,8 \%$ considera que la presencia de estudiantes con discapacidad en el aula no dificulta ni aumenta el trabajo de los profesores, aunque una alumna con discapacidad física matiza que quizá "con alumnos ciegos o sordos, aumente un poco el trabajo de los profesores, pero con la mayoría de estudiantes con discapacidad, no". El 11,2\% restante no se manifiesta ni por el sí ni por el no, un alumno con discapacidad física comenta:

No lo sé, depende de qué tipo de discapacidad tenga esa persona. Si es una discapacidad cognitiva, quizá no pueda seguir la clase, pero otro tipo de discapacidad, creo que no dificulta el trabajo de los profesores. Sé que hay una chica que tiene una discapacidad grandísima en cuanto a movilidad, que sólo mueve la cabeza, no sé si empezó historia, igual ella puede generar alguna dificultad porque se ha creado una beca específicamente para acompañar a esta chica.

En lo referente a las relaciones de los alumnos con discapacidad con sus profesores, un $77,7 \%$ piensa que nunca se ha sentido discriminado por ningún profesor. Una alumna con deficiencia auditiva señala: "una vez una profesora me preguntó qué me pasaba, pero no era de manera peyorativa". Sin embargo, un $22,3 \%$ señala que en algunas ocasiones sí ha sentido cierta discriminación por parte del profesorado. Una alumna con discapacidad psíquica comenta: 
Un profesor me hizo sentir tan mal, que sufri un bajón de tensión tan fuerte que tuve que permanecer hospitalizada dos días... Estaba en su despacho para hablar con él de mi caso y él creyó que iba a fardar delante de mis compañeros de contar con privilegios en la asignatura; entonces, me llamó de nuevo y se dirigió a mí con malos modales. Me duele que porque haya gente que mienta para conseguir favores del profesorado, cuando una persona realmente está mal, le toca recibir la regañina del profesor, cansado de que la gente "le vaya con historias.

Otra alumna, en este caso, con deficiencia visual, indica que se ha sentido discriminada por parte de un profesor que le preguntó -según comenta-, "con un tono bastante prepotente y desde mi punto de vista bastante prejuicioso: ¿por qué estudias magisterio tú si nunca vas a poder dar clase? Eso me pareció mal, esa pregunta estaba fuera de lugar".

\section{Relación con el resto de compañeros}

Al preguntar a los alumnos entrevistados si alguna vez se habían sentido discriminados por sus compañeros, aproximadamente la mitad se decantaron por el sí y la otra mitad por el no, aunque sus respuestas, en la mayor parte de los casos, no fueron rotundas. Un $55,5 \%$ de los estudiantes entrevistados considera que sí se ha sentido discriminado por sus compañeros en alguna ocasión, aunque los motivos expuestos son muy diferentes en cada persona. Una alumna con discapacidad psíquica comenta: "el rechazo por parte de mis compañeros me ha hecho en varias ocasiones pensar en dejar la carrera en León para empezar de nuevo en otro sitio”.

Otros alumnos consideran que existe discriminación, pero está oculta; una alumna con discapacidad física señala: "de manera directa no, pero indirectamente, a veces hay algunas risas por debajo. También, cuando hay que hacer trabajos en grupo, yo me quedo sin grupo porque todos tienen ya sus grupos hechos, entonces, algunos profesores me dicen que puedo hacer el trabajo sola”. Una opinión similar manifiesta otra alumna con deficiencia visual, que indica:

Creo que no hay una discriminación de manera explícita, pero si hay una discriminación de manera implícita. La gente da por hecho que, por el hecho (valga la redundancia) de ser discapacitada, no voy a tener los mismos intereses, las mismas curiosidades, el mismo afán de salir y las mismas necesidades que puedan tener ellos, entonces creo que ellos a veces no entienden que detrás de las gafas de sol se esconde una persona... La verdad es que amigos, según el concepto de amistad que mi mente abarca, creo que no he tenido en mi vida un amigo verdadero.

Otra alumna con deficiencia visual afirma: "sí hay algún comentario peyorativo, pero yo lo asimilo más bien a la edad de la gente, a la inmadurez. Hay algún comentario peyorativo, pero no específicamente hacia mi, son por ejemplo, comentarios peyorativos porque hay plazas reservadas para discapacitados".

No obstante, comenta que la relación con sus compañeros es buena a pesar de la diferencia de edad que existe entre ellos. Otra alumna, en este caso, con discapacidad física, introduce un nuevo concepto, el de la "autodiscriminación" y señala: 
A nivel de apuntes de clase, no noto discriminación, pero a la hora de ir a tomar un café o ir a las fiestas universitarias, sí... También, lo que yo sufrí mucho es la "discriminación pasiva", es decir, que nosotros mismos nos discriminamos, dices: ¿para qué voy a salir yo?, si ellos van a llegar a las seis de la mañana y yo a las tres, como mucho, me voy a ir y voy a tener que ir sola desde donde estemos o coger un taxi; entonces, ¿para qué voy a salir? Tendemos a discriminarnos.

El 44,5\% restante, indica que no se ha sentido discriminado por sus compañeros; una alumna con deficiencia auditiva comenta: "algunos compañeros se 'cortan' un poco a la hora de preguntar por la discapacidad, como si fuera un tema que no deben tratar, pero otros no han tenido ningún problema. Yo desde luego, si me preguntan, se lo cuento".

En lo referente a la existencia de limitaciones o dificultades por parte de los compañeros para iniciar una conversación, el $77,7 \%$ de los alumnos entrevistados indica no percibir ningún tipo tensión a la hora de conocer a sus compañeros; un alumno con discapacidad física comenta: "ellos tienen más reparo porque no saben cómo vas a reaccionar tú. Yo por mi forma de ser, hago el tonto o alguna bobada y les doy más margen para que hablen. De todas maneras, es un proceso que lleva su tiempo, igual que si no tienes una discapacidad; no puedes llegar el primer día y pretender hablar con todos".

El cambio, el 22,3\% restante señala que sí ha percibido algún tipo de dificultad para iniciar una conversación con él. Una alumna con deficiencia visual comenta que a medida que pasan los años en la Universidad, esas dificultades van desapareciendo: " $a l$ principio hay un poco de miedo porque no saben cómo tratarme, pero yo como soy tan charlatana, cuando ven que me río de mí misma, se rompe un poco el hielo. Al principio si que sentí un poco de soledad, pero ahora ya no". Otra alumna con deficiencia visual indica: "normalmente soy siempre yo la que toma la iniciativa para comenzar las conversaciones porten tengo un gran afán de socialización y de conocer gente, pero a veces, veo que existe ese miedo a que yo no pueda tener los mismos intereses y las mismas necesidades que ellos".

Sobre la sensibilización de los estudiantes universitarios, un 55,5\% de los alumnos entrevistados considera que, en general, los estudiantes están sensibilizados para facilitar la estancia de los alumnos con discapacidad en la Universidad. Un 11,1\% piensa que la mitad del alumnado está sensibilizado y la otra mitad, por desgracia, no. $\mathrm{Y}$ un 33,4\% señala que la mayor parte de los alumnos universitarios no está sensibilizada con la situación de los estudiantes con discapacidad; una alumna con deficiencia visual indica: " pienso que se deberían dar cursillos intensivos de educación para la ciudadanía porque en mi clase, que estudiamos educación especial, me parece patético el tratamiento que mucha gente da a la educación especial: se ríen, lo tratan con frivolidad, con absoluta indiferencia. Veo que falta vocación, conocimiento y en definitiva, falta sensibilidad".

Otra alumna, en este caso con discapacidad psíquica comenta: "la gente ve a un discapacitado y se queda mirando fijamente. Igual ya no es como antes, que miraban 
mal y cuchicheaban, pero ahora, estoy segura de que no quieren acercarse y crear un vínculo con un discapacitado porque es como un lastre en sus vidas".

En esta misma línea se encuentran los resultados obtenidos por Alcedo, Aguado Real, González y Rueda (2007) en la Universidad de Oviedo, donde los alumnos entrevistados realizan una demanda generalizada sobre dos aspectos: por un lado, reclaman materiales y recursos adaptados a sus necesidades y, por otro, la necesidad de proporcionar más información a la comunidad universitaria sobre la discapacidad, las posibilidades, dificultades y las necesidades

En cuanto a la relación de los alumnos entrevistados con otros compañeros con discapacidad, un $44,4 \%$ indica que no conoce a ningún estudiante con discapacidad, otro $44,4 \%$ señala que conoce a alguno, pero a muy pocos y el $11,2 \%$ restante comenta que sí tiene relación con otros compañeros con discapacidad. Una alumna con discapacidad física sugiere: "a veces he pensado que estaría bien hacer una reunión o una cena para que los alumnos con discapacidad nos conociéramos".

El 55,5\% de los alumnos entrevistados indica que ha acudido en alguna ocasión a la Unidad de Apoyo al estudiante con discapacidad, bien para solicitar información sobre las ayudas que existen para este colectivo o bien porque han sido citados por los profesionales que trabajan en este servicio. Un alumno con discapacidad física indica: "todo el asesoramiento que necesité, lo resolvieron bien". Sin embargo, una alumna con discapacidad psíquica comenta: "pienso que su papel (el de la Unidad de Apoyo) en la Universidad, no sirve para nada. Al menos, la persona que trabaja allí no ejerce como debiera según el puesto que ocupa". Un 33,3\% señala que nunca ha acudido a la Unidad de Apoyo a pesar de que sabe que existe.

Una alumna con discapacidad visual indica: "mi estancia en la Universidad ha sido toda a través de los apoyos familiares, no he tenido ningún apoyo externo". El 11,2\% restante comenta que no ha acudido físicamente al edificio donde está ubicada la Unidad de Apoyo al estudiante con discapacidad, pero que, si necesita algo, está en contacto con la persona que trabaja allí a través de correo electrónico.

\section{Participación en actividades y asociaciones}

Respecto a la colaboración con asociaciones, un $66,6 \%$ indica que no pertenece a ninguna asociación relacionada con su discapacidad y el 44,5\% restante comenta que sí pertenece a asociaciones vinculadas con su tipo de discapacidad; algunos estudiantes señalan que gracias a ellas han encontrado un trabajo (alumna con discapacidad física), otros indican que su asociación "no le aporta gran cosa" (alumna con deficiencia visual) y otros comentan que les ayudan con las adaptaciones de estudio. "Todos los ciegos tenemos que estar afiliados a la ONCE, es un poco ridículo que no lo estés porque no te supone ningún coste y te da algunos beneficios, no digo muchos, pero sí algunos" (alumna con deficiencia visual).

En lo referente a las actividades deportivas y lúdicas (conciertos, talleres, teatro...) organizadas por la Universidad, un $44,4 \%$ indica que nunca ha participado en nada; un $22,2 \%$ señala que sólo ha acudido ocasionalmente a algún concierto u obra de teatro y el $33,4 \%$ restante comentan que participa en actividades deportivas. Una alumna con 
deficiencia visual señala: "este año he tomado la iniciativa de acudir a clases de yoga, que es un servicio ofertado por el departamento de deportes de la Universidad. Está siendo una experiencia bastante fructifera para mi". La experiencia de otra alumna, en este caso con discapacidad física, no fue tan positiva, quizá porque por su discapacidad, no tiene las mimas capacidades físicas que el resto de compañeras, algo que no es fácil de admitir en equipos competitivos. Ella comenta:

Intenté formar parte del equipo de baloncesto de la Universidad, fui a entrenar el primer día, pero el responsable del equipo no quería que yo estuviera allí y convenció al entrenador para que me echara. El único partido al que fui, estuve todo el tiempo en el banquillo, no jugué nada. Así que compré ropa y zapatillas para entrenar y ahí lo tengo, todo nuevo, en el armario.

Hay que dejar constancia de que ninguno de los alumnos entrevistados ha participado en ambos tipos de actividades; los que practican algún deporte, no participan en actividades lúdicas y viceversa.

Ninguno de los alumnos entrevistados ha participado en programas de movilidad estudiantil. Un 44,4\% comentan que no están interesados en este tipo de actividades, una alumna con deficiencia visual señala: "la verdad es que no tengo interés en ello... bueno, interés sí que existe por el hecho de conocer una cultura nueva y poner en práctica el idioma que estudio, pero yo creo que hay un cierto miedo en mí a desplazarme, a dejar esto. Es decir, que se juntan las dos cosas". El 55,6\% restante indican que le gustaría participar en algún programa de movilidad, aunque no sabe si llegará a hacerlo algún día. Otra alumna con deficiencia visual comenta: "sí que me gustaría, pero yo ya tengo una edad, no creo que llegue yo a tanto. Aunque me parece muy interesante; si me cubriera los gastos, sí que me lo pensaría”.

\section{Propuestas de mejora}

Al preguntar a los alumnos entrevistados sobre las medidas que debería tomar la Universidad para mejorar el acceso y la integración de los estudiantes con discapacidad, hemos obtenido respuestas muy similares. En cuanto al acceso, proponen:

- "A los alumnos que lo necesiten, ponerles una persona para que les ayuden" (alumna con deficiencia auditiva).

- "Adaptar los edificios, por lo menos en los que hay estudiantes con discapacidad y no sólo los de nueva construcción” (alumna con discapacidad física).

- "Poner un autobús (adaptado) que acceda al campus y que eliminen las escaleras de acceso a las facultades que no tienen ascensores. Yo pediría también la adaptación de los baños, porque para la gente que está en silla de ruedas, los baños tienen que ser de 45 centímetros de altura y son poquisimas las facultades que lo tienen" (alumno con discapacidad física). 
- "A nivel de edificios, lo tengo muy claro: la manera de que se conozcan las barreras es preguntando a los alumnos con discapacidad. Yo entiendo que no pueden hacer "pum" y con una varita mágica ponértelo todo en quince días, pero este curso se puede sacar una partida presupuestaria para este tema, en lugar de gastarlo, como muchas veces ocurre, en tonterías. Que digan: vamos a adaptar estas dos facultades y esta parte común y el próximo año que hagan lo mismo en otras facultades" (alumna con discapacidad física).

- "Quitar obstáculos: hay que arreglar un poco el pavimento, que está todo lleno de losetas que se mueven y cuando llueve te ponen pingando; eso sin hablar de los aspersores, que cuando los encienden, si vas sólo o te descuidas, te duchan. Los bancos, que hay por todas partes, no están bien señalizados y dentro de las facultades, si no vas con alguien, no puedes enterarte de lo que pone en los carteles. Las páginas web no son todas accesibles. También querría destacar la desinformación que hay dentro de la facultad, que preguntas cosas a veces y en secretaría no tienen ni idea porque no se han informado" (alumna con deficiencia visual).

- "Sería importante bajar todos los bordillos de los pasos de cebra, que hay muchos todavía en la Universidad. También pediría que en todas las facultades hubiera un baño adaptado para minusválidos y ascensores. Las clases en pendiente, me parece que es algo ya imposible de modificar (alumno con discapacidad física)".

Como medidas para mejorar la integración, los alumnos entrevistados destacan:

- "Hacer reuniones o congresos en los que los alumnos sin discapacidad puedan participar y asi podamos intercambiar roles, por ejemplo, que ellos se pongan en la piel de un ciego o una persona sorda" (alumna con discapacidad física).

- "Organizar charlas para los estudiantes 'normales', para que no sean tan egoistas y traten mejor a las personas con discapacidad" (alumna con discapacidad física).

- "Dar charlas informativas, por ejemplo, que las dieran personas de las diferentes asociaciones (ONCE, ASPAYM...) y si no va nadie, entonces que den créditos o un canapé después" (alumno con discapacidad física).

- "En cuanto a la integración, yo creo que sensibilizar en la Universidad es un poco difícil, yo creo que hay que sensibilizar antes porque a veces, por ejemplo, pasan dos niños pequeños a tu lado y empiezan a hacerte burla y los padres se quedan callados. Esto todavía se ve por la calle" (alumna con discapacidad física).

- "Organizar cursillos en los que se dieran a conocer experiencias particulares de personas con discapacidad, y así, se podría dar una mejor respuesta a la vida de estas personas; porque la psicología te dice algo general, algo que está constatado por sabios que lo han investigado, pero yo lo que quiero es 
una respuesta de conocimiento individual de las personas. Por ejemplo, que yo exponga mi caso, que diga, a pesar de ser ciega, yo soy una chica" (alumna con deficiencia visual).

\section{Conclusiones}

Después de realizar las entrevistas en profundidad a los alumnos con discapacidad que decidieron participar en este estudio, conversar con ellos sin una grabadora que pueda frenar la espontaneidad y observar su comportamiento en una actividad social; hemos llegado a la conclusión de que la mayor parte de los estudiantes con discapacidad de la Universidad de León (un 66,6\%) se encuentra integrada a pesar de que pueda haberse sentido discriminada por algún miembro de la comunidad universitaria en alguna ocasión puntual. El 33,4\% restante no está integrado; en este caso, coinciden en ser alumnos que tienen su discapacidad desde el momento de su nacimiento o los primeros años de sus vidas; pero este no es un aspecto significativo, pues otros estudiantes con discapacidades congénitas, están perfectamente integrados en la Universidad. Podemos concluir que la edad, el sexo, el grado y el momento de aparición de la discapacidad no parecen condicionar el nivel de integración de los alumnos.

Por otro lado, hemos observado que una gran parte de los estudiantes con discapacidad se sienten solos. Aunque algunos alumnos en un principio se declaran integrados, al tratar este tema en profundidad, sus comentarios delatan una gran soledad. Por este motivo, consideramos importante trabajar más la integración de los alumnos con discapacidad en la comunidad universitaria y su relación entre ellos, aspecto que puede parecer segregante, pero que los estudiantes entrevistados consideran algo muy positivo para ellos.

También hemos notado en los estudiantes entrevistados un fuerte miedo hacia lo desconocido, de ahí su poco interés por participar en las actividades organizadas por la Universidad ni en los programas de movilidad estudiantil. En algún caso estos miedos son el reflejo de un excesivo proteccionismo familiar como consecuencia de la discapacidad.

Las relaciones con los profesores, en general, son buenas; la mayor parte de los alumnos entrevistados nunca se ha sentido discriminada por los profesores y siente que le tratan como a uno más de la clase (89\%), aunque reconoce que a los docentes les falta información y recursos para poder adecuar la metodología de las clases a las características de cada alumno. Este dato se contradice con otro apartado en el que la mayor parte de los alumnos considera que la presencia de estudiantes con discapacidad en el aula no aumenta ni dificulta el trabajo de los profesores (89\%).

En esta época de crisis económica que estamos viviendo, conviene destacar que un $45 \%$ de los alumnos entrevistados considera que hoy en día es más fácil encontrar un trabajo si tienes una discapacidad (por las ayudas que reciben las empresas) que si no la tienes. 
En relación con el resto de estudiantes, llama la atención que más de la mitad de los entrevistados se han sentido discriminados en alguna ocasión por sus compañeros, por eso debemos señalar que la sensibilización de la comunidad universitaria ante el tema de la discapacidad, aún es una asignatura pendiente. Todas las campañas informativas, cursos, seminarios y jornadas que se realicen en este ámbito son de gran utilidad porque fomentan que la integración de los alumnos con discapacidad en la Universidad se vaya consolidando poco a poco.

Para finalizar, destacamos que todos los alumnos entrevistados han contestado ampliamente cuando les hemos preguntado por las medidas que debería tomar la Universidad para mejorar el acceso y la integración del alumnado con discapacidad. La eliminación de barreras arquitectónicas y adaptación de los edificios ha sido uno de los puntos más destacados. Otra demanda que realizan es la posibilidad de que los alumnos que lo necesiten tengan una persona para que les ayuden, sugieren un becario o un voluntario para realizar esta labor.

En lo referente a la integración, todos los entrevistados coinciden en demandar más información sobre las discapacidades para toda la comunidad universitaria. Charlas, reuniones o congresos para los alumnos y cursos de formación en atención a personas con discapacidad para los profesores.

\section{Referencias bibliográficas}

ALCANTUD MARÍN, F. (1995). Estudiantes con discapacidades integrados en los estudios universitarios: notas para su orientación. En J. Mayor (dir.), Manual de Asesoramiento y Orientación Vocacional (pp. 455-470). Madrid: Editorial Síntesis

ALCANTUD MARÍN, F. (1997). Universidad y diversidad. Valencia: Universitat de Valencia.

ALCANTUD MARÍN, F., ÁVILA CLEMENTE, V. Y ASENSI BORRÁS, M.C. (2000). La integración de estudiantes con discapacidad en los estudios superiores. Valencia: Universitat de Valencia Estudi General.

ALCEDO RODRÍGUEZ,M.A., AGUADO DÍAZ, A.L., REAL CASTELAO, S., GONZÁLEZ GONZÁLEZ, M. Y RUEDA RUIZ, B (2007). Una revisión actualizada de la situación de los estudiantes con discapacidad en la universidad. Anuario de Psicología Clínica y de la salud, 3, 7-18.

ARNAL, J., DEL RINCÓN, D. Y LATORRE, A. (1994). Investigación educativa. Fundamentos y metodología. Barcelona: Editorial Labor.

BILBAO LEÓN, M.C. (2008). La integración de personas con discapacidad en la Educación Superior. Percepciones y demandas de docentes y estudiantes en la Universidad de Burgos. Tesis doctoral sin publicar. Universidad de Burgos.

CASTELLANA ROSELL, M. Y SALA BARS, I. (2006). La inclusión de los estudiantes con discapacidad en la universidad: un reto para la universidad española en el nuevo espacio europeo de la educación superior. Aloma, 18, 209-227. 
CASTELLANA ROSELL, M. Y SALA BARS, I. (2006). Estudiantes con discapacidad en la universidad: cómo atender esta diversidad en el aula. Barcelona: Fundació Blanquerna Assistencial i de Serveis (Universidad Ramon Llull).

DE LA RED VEGA, N., DE LA PUENTE LLORENTE, R., GÓMEZ NIETO, M.C. Y CARRO SANCRISTÓBAL, R. (2002). El acceso a los estudios superiores de las personas con discapacidad física y sensorial. Valladolid: Secretariado de Publicaciones e intercambio editorial de la Universidad de Valladolid.

DEL RINCÓN, D., LATORRE, A., ARNAL, J. Y SANS, A. (1995). Técnicas de investigación en ciencias sociales. Madrid: Editorial Dykinson.

DÍAZ JIMÉNEZ, G. (2004). Los estudiantes con discapacidad en la Universidad de Las Palmas de Gran Canaria. Las Palmas de Gran Canaria: Vicerrectorado de Planificación y Calidad de la Universidad de Las Palmas de Gran Canaria.

DÍEZ, E. (2005). Los universitarios con discapacidad en el espacio europeo de educación superior. I Congreso Nacional sobre Universidad y Discapacidad. Salamanca: Gráficas LOPE

GÓMEZ MONEDERO, J.A. (2003). Alumnos con discapacidad en el ámbito universitario. En R. Casado Muñoz y A. Cienfuentes García, El acceso al empleo y a la universidad de las personas con discapacidad. Barreras y Alternativas (pp. 145-151). Burgos: Servicio de Publicaciones de la Universidad de Burgos.

LÓPEZ, V., FELIPE, E., RUIZ, I. Y VICENTE, F. (2006). Necesidades, apoyos y satisfacción de estudiantes universitarios con discapacidad: un estudio cualitativo. En II Congreso Nacional sobre Universidad y Discapacidad. XI Reunión del Real Patronato sobre discapacidad (pp. 274-283). Madrid: Vicerrectorado de Estudiantes, Universidad Complutense de Madrid.

MILES, M.B. \& HUBERMANN, A. M. (1994). Qualitative data analysis. An expanded sourcebook (2nd editicon).Thousand Oaks, CA: Sage Publications.

PERALTA, A. (2007). Libro Blanco sobre universidad y discapacidad. Madrid: Real Patronato sobre Discapacidad/ M.E.C./ Fundación Vodafone/ANECA/ CERMI.

PÉREZ SERRANO, G. (1994). Investigación cualitativa. Retos e interrogantes. Madrid: Editorial La Muralla.

PERALTA, A. (2007). Libro Blanco sobre universidad y discapacidad. Madrid: Real Patronato sobre Discapacidad/ M.E.C./ Fundación Vodafone/ANECA/ CERMI.

PÉREZ SERRANO, G. (1994). Investigación cualitativa. Retos e interrogantes. Madrid: Editorial La Muralla.

POLO SÁNCHEZ, M. Y LÓPEZ JUSTICIA, M.D. (2005). Barreras de acceso al medio físico de los estudiantes con discapacidad motora de la Universidad de Granada. Revista electrónica de Investigación Psicoeducativa, 3 (3), 121-132. 
RODRÍGUEZ, G., ROMERO, J.F. Y LUQUE, D. J. (2005). Accesibilidad y Universidad: un estudio descriptivo. Intervención Psicosocial. Revista sobre igualdad y calidad de vida, 14 (2), 209-222.

SÁNCHEZ PALOMINO, A. (coord.) (2009). Integración educativa y social de los estudiantes con discapacidad en la Universidad de Almería. El Ejido: Editorial Universidad de Almería.

\section{Correspondencia con la autora}

Eva Nava Caballero

Universidad de León

e-mail: evanava7@hotmail.com 